\title{
Kunzea ambigua (Sm.) Druce and Kunzea flavescens C.T. White and W.D. Francis Essential Oils Inhibit the Growth of Some Bacterial Triggers of Inflammatory Diseases
}

\author{
Célia Barillot ${ }^{1,2}$, Ian Edwin Cock ${ }^{1,3, *}$ \\ 'Environmental Futures Research Institute, Griffith University, Brisbane, AUSTRALIA. \\ ${ }^{2} S c h o o l$ of Biology, Ecole de Biologie Industrielle (EBI), Cergy, FRANCE. \\ school of Environment and Science, Griffith University, Brisbane, AUSTRALIA.
}

\begin{abstract}
Introduction: Kunzea ambigua (Sm.) Druce and Kunzea flavescens C.T. White and W.D. Francis are endemic Australian plants. Decoctions, infusions and essential oils produced from the leaves were used traditionally to treat a variety of bacterial diseases. Despite this, these species have not been rigorously examined for antibacterial properties against many pathogens. Methods: The antimicrobial activity of $K$. ambigua and $K$. flavescens essential oils and a $K$. ambigua hydrosol was investigated by disc diffusion and liquid dilution MIC assays against a panel of pathogenic bacteria. Toxicity was determined using the Artemia franciscana nauplii bioassay. Results: $K$. ambigua and $K$. flavescens essential oils displayed noteworthy growth inhibitory activity against $A$. baylyi, K. pneumonia, $P$. mirabilis and $P$. aeruginosa (MIC values substantially $<1000 \mu \mathrm{g} / \mathrm{mL}$ ). Indeed, MIC values as low as $33 \mu \mathrm{g} / \mathrm{mL}$ were noted against $P$. aeruginosa. Noteworthy growth inhibitory activity was also noted for the $K$. ambigua hydrosol against $A$. baylyi and $P$. aeruginosa. All extracts were determined to be non-toxic in the Artemia franciscana nauplii bioassay, indicating their safety for internal use as well as for topical uses. Conclusion: The lack of
\end{abstract}

toxicity of the Kunzea spp. extracts and their growth inhibitory bioactivity against a panel of pathogenic bacteria partially validate the traditional usage of these species to treat bacterial diseases and indicate their potential in the development of antiseptic agents.

Key words: Myrtaceae, Tick bush, White Kunzea, Rheumatoid arthritis, Ankylosing spondylitis, Multiple sclerosis, Australian plants, Antibacterial activity.

\section{Correspondence:}

Dr. Ian Edwin Cock ${ }^{1.3}$

${ }^{1}$ Environmental Futures Research Institute, Griffith University, Brisbane, AUSTRALIA.

${ }^{3}$ School of Environment and Science, Griffith University, Brisbane, AUSTRALIA.

Phone no: +61737357637

E-mail: i.cock@griffith.edu.au

DOI: 10.5530/pc.2021.2.17

\section{INTRODUCTION}

Plants produce a wide variety of compounds, which in addition to giving them characteristic pigment, odour and flavour characteristics, may also have antimicrobial properties. ${ }^{1}$ For thousands of years, traditional plant derived medicines have been used in most parts of the world and their use in fighting microbial disease is becoming the focus of intense study. ${ }^{2,3}$ Whilst much of the research into traditional medicinal plant use has focused on Asian, ${ }^{4}$ African ${ }^{5}$ and South American ${ }^{6}$ plants, the therapeutic potential of the flora of Australia has been recognised for many thousands of years. The first Australians had well developed ethnopharmacological systems and understood the therapeutic properties of a wide variety of aromatic Australian plants. ${ }^{7}$ Despite this, relatively few studies have rigorously examined the antibacterial activity of Australian native plants, although recently there has been increased study in this field.

The development of new antibiotic therapies is particularly urgent. The recent establishment of bacterial pathogens that are either extremely (XDR) or totally resistant (TDR) to common clinically used antibiotics ${ }^{8}$ has resulted in the need to develop new and effective antibiotic chemotherapies. There are now limited therapeutic options for many diseases caused by bacterial pathogens and the situation is expected to worsen in the future as bacteria exchange resistance genes. Indeed, the development of alternative antibacterial treatment modalities has become crucial and is considered by the World Health Organisation (WHO) to be one of the most serious challenges facing medical science. ${ }^{9}$ For reasons reviewed elsewhere, ${ }^{8}$ it is unlikely that the previous methods of antibiotic discovery/development will be as successful in the future and new treatment modalities are urgently required. Traditional medicines and herbal remedies have great potential for antimicrobial drug development and there has recently been a substantial increase in interest in this field. ${ }^{10-24}$

The healing properties of Australian plants of the family Myrtaceae have long been understood by Australian Aborigines. More recently, the bacterial growth inhibitory properties of many genera within the family Myrtaceae have been examined and documented. In particular, Callistemon spp., ${ }^{25}$ Eugenia spp., ${ }^{7}$ Kunzea spp.,${ }^{7,26}$ Leptospermum spp. ${ }^{7,27,28}$ and Syzygium spp. ${ }^{29-31}$ have been reported to inhibit the growth of a wide panel of bacteria, including many medicinally important pathogens. The genus Kunzea (family Myrtaceae) consists of approximately 50 species of small to medium shrubs which are native to Australia, with 2 species also occurring in New Zealand. Perhaps the best known Kunzea spp. are Kunzea ambigua (Sm.) Druce (commonly known as tick bush; Figure 1a), Kunzea ericoides (A.Rich) Joy Thomps. (commonly known as Kānuka, white tea-tree, Burgan), Kunzea pomifera F. Muell. (commonly known as muntries, emu apples, native cranberries) and Kunzea flavescens C.T. White and W.D. Francis (commonly known as white Kunzea; Figure 1b). These species have each been reported to inhibit bacterial growth. ${ }^{7,26,32-34}$ However, most studies have tested Kunzea spp. solvent extracts and only a few have screened essential oils against human pathogens. ${ }^{32-34}$

Several interesting phytochemical components have been identified in Kunzea spp. extracts and essential oils. In particular, several terpenoid components including a-pinene (Figure 1c), 1,8-cineole (Figure 1d), bicyclogermacrene (Figure 1e), spathulenjol (Figure 1f), globulol (Figure $1 \mathrm{~g}$ ) and viridflorol (Figure 1h) have been identified in Kunzea spp. extracts and essential oils. ${ }^{33,35,36}$ Interestingly, those studies also reported broad spectrum antibacterial and anti-protozoal activity for the 


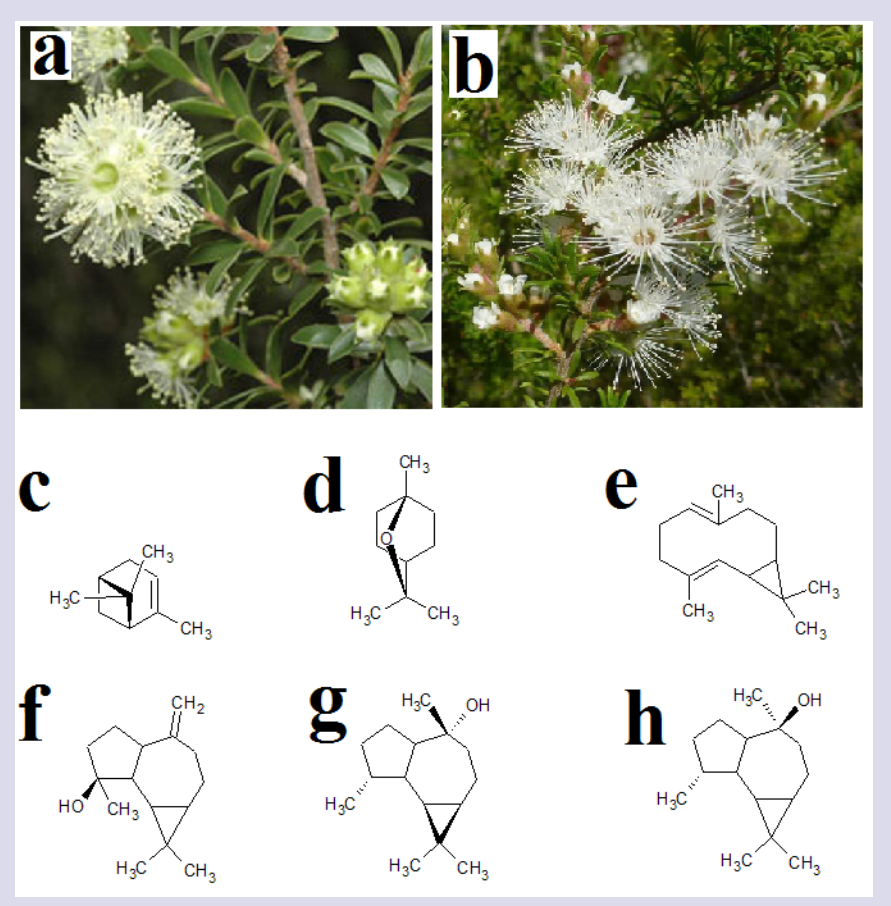

Figure 1: (a) K. flavescens and (b) K. ambigua leaves and flowers, as well as the chemical structures of (c) a-pinene, (d) 1,8-cineole, (e) bicyclogermacrene, (f) spathulenjol, (g) globulol and (h) viridflorol.

bark extracts and all of the isolated compounds. Indeed, the extract and isolated compounds inhibited the growth of all bacteria and protozoa screened. Broad spectrum antifungal activity was also reported, albeit at doses which would indicate only moderate to low growth inhibitory activity. Despite these promising earlier studies, examination of the antibacterial properties and phytochemistry of many other Kunzea spp. (and of the essential oils produced from them) is lacking. The current report was undertaken to screen $K$. ambigua and $K$. flavescens essential oils for growth inhibitory properties against a panel of pathogenic bacteria, and compare the activities to those of a commercial hydrosol.

\section{MATERIALS AND METHODS}

\section{Kunzea ambigua (Sm.) Druce and Kunzea flavescens C.T. White and W.D. Francis preparations}

Kunzea ambigua (Sm.) Druce and Kunzea flavescens C.T.White and W.D. Francis essential oils was obtained from Biodistributors, Australia. K. ambigua hydrosol was purchased from Aphrodite Australia. Five millilitre volumes of each sample were extensively dried by freeze drying for $48 \mathrm{~h}$ until no decrease in mass was noted on repeated measurements. All samples were subsequently emulsified in $5 \mathrm{~mL}$ of sterile deionised water containing $1 \%$ DMSO and stored at $4^{\circ} \mathrm{C}$ until use.

\section{Qualitative phytochemical studies}

Phytochemical analysis of the Kunzea spp. essential oils and hydrosol for the presence of saponins, phenolic compounds, flavonoids, phytosteroids, triterpenoids, cardiac glycosides, anthraquinones, tannins and alkaloids was conducted by previously described assays. ${ }^{26-28}$

\section{Antioxidant capacity}

The antioxidant capacity of each sample was assessed using the DPPH free radical scavenging method ${ }^{37}$ with modifications. Briefly, DPPH solution was prepared fresh each day as a $400 \mu \mathrm{M}$ solution by dissolving DPPH (Sigma) in AR grade methanol (Ajax, Australia). A $2 \mathrm{~mL}$ aliquot of each sample was evaporated and the residue resuspended in $2 \mathrm{~mL}$ of methanol. Each sample was added to a 96 well plate in 5, 10, 25, 50, $75 \mu \mathrm{L}$ volumes in triplicate. Methanol was added to each well to give a volume of $225 \mu \mathrm{L}$. A volume of $75 \mu \mathrm{L}$ of the fresh $\mathrm{DPPH}$ solution was added to each well to give a total reaction volume of $300 \mu \mathrm{L}$. Ascorbic

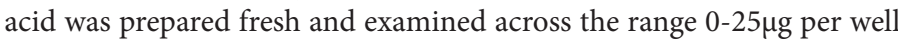
as a reference and the absorbance's were recorded at $515 \mathrm{~nm}$. All tests and controls were tested in triplicate. The antioxidant capacity based on DPPH free radical scavenging ability was determined for each extract and expressed as $\mu \mathrm{g}$ ascorbic acid equivalents per gram of original plant material extracted.

\section{Antibacterial screening}

\section{Test micro-organisms}

All media was purchased from Oxoid Ltd., Australia. The reference strains of A. baylyi (ATCC21721), Klebsiella pneumoniae (ATCC31488), Proteus mirabilis (ATCC21721), Proteus vulgaris (ATCC21719) and Pseudomonas aeruginosa (ATCC39324) were purchased from American Tissue Culture Collection (ATCC), USA. Clinical isolate microbial strains of Alcaligenes feacalis, Bacillus cereus, Enterobacter aerogenes, Enterococcus faecalis, Escherichia coli, Klebsiella pneumonia, Proteus mirabilis and Pseudomonas aeruginosa were obtained from Ms Michelle Mendell and Ms Jane Gifkins, Griffith University. All stock cultures were subcultured and maintained in nutrient broth at $4^{\circ} \mathrm{C}$.

\section{Evaluation of antimicrobial activity}

Antimicrobial activity of the Kunzea spp. essential oils and hydrosol was determined using a modified disc diffusion assay. ${ }^{22,38}$ Briefly, $100 \mu \mathrm{L}$ of the each bacterial suspension in log phase was spread onto individual nutrient agar plates and the extracts were tested for antibacterial activity using $5 \mathrm{~mm}$ sterilised filter paper discs. The discs were each infused with $10 \mu \mathrm{L}$ of the individual plant extract, allowed to dry and placed onto the inoculated plates. The plates were allowed to stand at $4^{\circ} \mathrm{C}$ for $2 \mathrm{~h}$ before incubation at $37^{\circ} \mathrm{C}$ for $24 \mathrm{~h}$. The diameters of the zones of inhibition (ZOIs) were measured to the closest whole millimetre. Each assay was performed three times in triplicate $(n=9)$. Mean values $( \pm$ SEM) are reported in this study. Standard discs of ampicillin $(10 \mu \mathrm{g})$ and chloramphenicol $(10 \mu \mathrm{g})$ were obtained from Oxoid, Australia and were used as positive controls to compare antibacterial activity. Filter discs infused with $10 \mu \mathrm{L}$ of distilled water were used as a negative control.

\section{Minimum inhibitory concentration (MIC) determination}

The minimum inhibitory concentration for each extract was determined using liquid dilution MIC assays and solid phase agar disc diffusion assays.

\section{Microplate liquid dilution MIC assay}

A standard liquid dilution MIC assay ${ }^{39}$ was used to evaluate the bacterial growth inhibitory activity of the essential oils, hydrosol and conventional antibiotic. Briefly, log phase bacterial cultures were diluted to produce a McFarlands inoculation culture. A $100 \mu \mathrm{L}$ volume of sterilized nutrient broth was dispensed into all wells of a 96 well micro-titre plate. A volume of $100 \mu \mathrm{L}$ of the plant extracts or conventional antibiotics was subsequently dispensed into separate wells of the top row of the plate. A negative control (nutrient broth), sterile control (broth without bacteria) and a sample-free culture control (to ensure the media was capable of supporting microbial growth) were also included on all plates. Each test sample or control was serially diluted down each column on the plate by doubling dilution. The assay culture inoculum $(100 \mu \mathrm{L}$, containing 
approximately $1 \times 10^{6}$ colony forming units $(\mathrm{CFU}) / \mathrm{mL}$ ) was then added to all wells except the sterile control wells and incubated overnight at $37^{\circ} \mathrm{C}$. p-Iodonitrotetrazolium violet (INT, Sigma-Aldrich, Australia) was dissolved in sterile deionised water to a concentration of $200 \mu \mathrm{g} / \mathrm{mL}$. A $40 \mu \mathrm{L}$ volume of the INT solution was added into all wells and the plate was incubated for a further $6 \mathrm{~h}$ at $37^{\circ} \mathrm{C}$. The MIC was visually determined as the lowest dose at which colour development was inhibited.

\section{Disc diffusion MIC assay}

The minimum inhibitory concentration (MIC) of each extract was also quantified by disc diffusion assay. ${ }^{40,41}$ Graphs of the zone of inhibition (ZOI) versus $\ln$ concentration were plotted and MIC values were calculated by linear regression.

\section{Toxicity screening}

\section{Reference toxin for toxicity screening}

Potassium dichromate $\left(\mathrm{K}_{2} \mathrm{Cr}_{2} \mathrm{O}_{7}\right)$ (AR grade, Chem-Supply, Australia) was prepared as a $4 \mathrm{mg} / \mathrm{mL}$ solution in distilled water and was serially diluted in artificial seawater for use in the Artemia franciscana nauplii bioassay.

\section{Artemia franciscana nauplii toxicity screening}

Toxicity was tested using an adapted Artemia franciscana nauplii lethality assay. ${ }^{11,13}$ Briefly, $400 \mu \mathrm{L}$ of seawater containing approximately 43 (mean $42.6 \pm 10.6 ; n=125$ ) A. franciscana nauplii were added to wells of a 48 well plate and immediately used for bioassay. A volume of $400 \mu \mathrm{L}$ of diluted plant preparations or the reference toxin were transferred to the wells and incubated at $25 \pm 1^{\circ} \mathrm{C}$ under artificial light (1000 Lux). A $400 \mu \mathrm{L}$ seawater negative control was run in triplicate for each plate. All treatments were performed in at least triplicate. The wells were checked at regular intervals and the number of dead counted. The nauplii were considered dead if no movement of the appendages was detected within $10 \mathrm{sec}$. After $24 \mathrm{~h}$, all nauplii were sacrificed and counted to determine the total $\%$ mortality per well. The $\mathrm{LC}_{50}$ with $95 \%$ confidence limits for each treatment was determined using probit analysis.

\section{Statistical analysis}

Data are expressed as the mean \pm SEM of at least three independent experiments. One way ANOVA was used to calculate statistical significance between control and treated groups with a $P$ value $<0.01$ considered to be statistically significant.

\section{RESULTS}

\section{Extract/hydrosol yields and qualitative phytochemical screening}

Freeze drying the Kunzea spp. essential oils and hydrosol resulted in masses of dried material ranging from $2780 \mathrm{mg}$ (K. ambigua hydrosol) to $2980 \mathrm{mg}$ (K. ambigua essential oil) (Table 1). The dried extracts were resuspended in $5 \mathrm{~mL}$ of deionised water (containing 1\% DMSO), resulting in the extract concentrations shown in Table 1. Qualitative phytochemical studies showed that only low levels of polar polyphenolic compounds were detected in the essential oils and hydrosol. Due to their non-polar nature, these extracts would be expected to contain high levels of lipids, hydrocarbons etc. As our qualitative phytochemical studies did not screen for these compounds, they were not detected. Other techniques are required to further examine the nature of these non-polar components. Moderate to low levels of triterpenoids were also detected in the essential oils of both Kunzea species. Interestingly, we were unable to detect antioxidant content levels for either of the essential oils, and only a low antioxidant capacity was measured for the K. ambigua hydrosol.

\section{Antimicrobial activity}

To determine the growth inhibitory activity of the Kunzea spp. essential oils and hydrosol against the panel of pathogenic bacteria, aliquots (10 $\mu \mathrm{L}$ ) of each extract were screened in the disc diffusion assay. Noteworthy growth inhibitory activity was seen against several bacterial species (Figure 2). The essential oils were generally better inhibitors of bacterial growth, and the K. ambigua essential oil was generally better than the $K$. flavescens essential oil (as judged by ZOI). K. ambigua essential oil was a particularly good inhibitor of $A$. baylyi, with a ZOI of $8.3 \pm 0.4 \mathrm{~mm}$ recorded against the reference strain. Notably, only E. aerogines was resistant to each of the essential oils and the hydrosol.

The relative level of antimicrobial activity was further evaluated by determining the MIC values (Table 2) against the bacterial pathogens. The K. ambigua and $K$. flavescens essential oils were particularly effective at inhibiting the growth of $A$. baylyi, K. pneumonia, $P$. mirabilis and $P$. aeruginosa (MIC values substantially $<1000 \mu \mathrm{g} / \mathrm{mL}$ ). Indeed, MIC values as low as $33 \mu \mathrm{g} / \mathrm{mL}$ were noted against $P$. aeruginosa. Noteworthy growth inhibitory activity was also noted for the K. ambigua hydrosol against $A$. baylyi and $P$. aeruginosa. These growth inhibitory activities are especially interesting as $P$. aeruginosa is resistant against many antibiotics. Indeed, in our study, both the reference and clinical strains of this bacterium were completely resistant to ampicillin. The relatively high MIC value $(2.5 \mu \mathrm{g} /$ $\mathrm{mL}$ ) indicates that this bacterium is also resistant to chloramphenicol. A. baylyi, $K$. pneumoniae and $P$. mirabilis were similarly resistant to both antibiotic controls. Therefore, the Kunzea spp. preparations may be useful in treating infections caused by these bacteria. Previous studies have reported that $P$. mirabilis and $K$. pneumoniae can induce rheumatoid arthritis and ankylosing spondylitis respectively in genetically susceptible individuals. ${ }^{12,13,15}$ Additionally, A. baylyi and $P$. aeruginosa can induce multiple sclerosis in genetically susceptible people. ${ }^{42}$ Thus, the Kunzea spp. essential oils and hydrosol have potential in the prevention and treatment of these diseases, as well as other diseases caused by these bacteria. All other bacterial pathogens were either completely resistant to the Kunzea spp. essential oils and hydrosol,

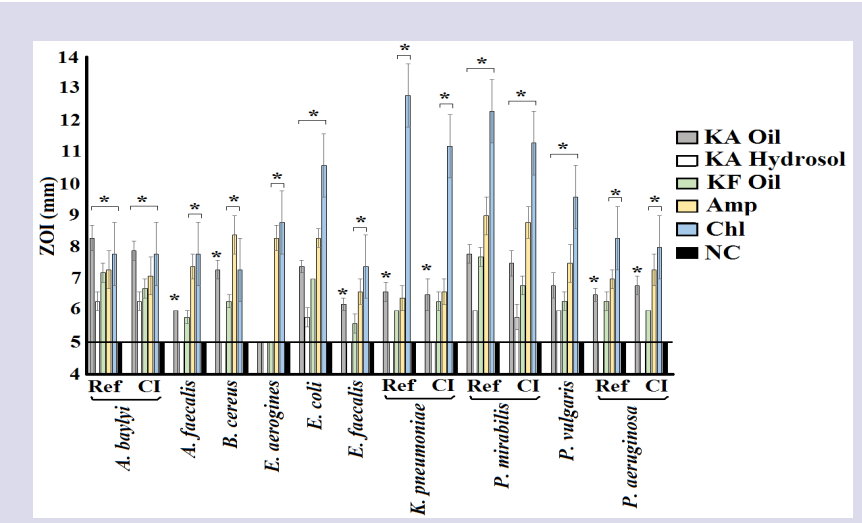

Figure 2: Antibacterial activity of Kunzea spp. essential oils and extracts, as well as ampicillin and chloramphenicol controls $(10 \mu \mathrm{g})$ measured as zones of inhibition $(\mathrm{mm})$ against bacterial pathogens. Results are expressed as mean \pm SEM of at least triplicate determinations. Ref $=$ reference strains; $\mathrm{Cl}=$ clinical isolate strains; $\mathrm{KA}=K$. ambigua; $\mathrm{KF}=K$. flavescens; $\mathrm{Amp}=$ ampicillin' $\mathrm{Chl}=$ chloramphenicol; $\mathrm{NC}=$ negative control. ${ }^{*}=$ results that are significantly different to the negative control. $5 \mathrm{~mm}$ line indicates the diameter of the disc. ${ }^{*}$ indicates results that are significantly different to the untreated control $(p<0.01)$. 
or displayed only low inhibitory activity (as judged by MIC values).

Interestingly, major differences were noted between the efficacy of the essential oils and the hydrosol between the disc diffusion and liquid dilution assays. The disc diffusion assay is reliant on the movement of compounds through an aqueous gel. Low polarity compounds do not readily diffuse through agar gels and low or fallacious results may be recorded using this method to quantify the activity of essential oils. No such limitation to diffusion occurs for liquid dilution assays and the results obtained from those assays may be considered more accurate for non-polar compounds and solutions.

\section{Quantification of toxicity}

The toxicity of the Kunzea spp. essential oils and hydrosol was initially tested in the Artemia franciscana nauplii bioassay at a concentration of $2000 \mu \mathrm{g} / \mathrm{mL}$ (Figure 3). The K. ambigua essential oil induced 100\% mortality in the Artemia nauplii following $24 \mathrm{~h}$ exposure, indicating some toxicity toxic. In contrast, the K. flavescens essential oil induced only approximately $20 \%$ mortality and the K. ambigua hydrosol did not induce mortality significantly different to that seen for the seawater control. As samples with $\mathrm{LC}_{50}$ values $<1000 \mu \mathrm{g} / \mathrm{mL}$ towards Artemia nauplii are defined as being toxic, ${ }^{11,13,43}$ both the K. flavescens essential oil and the K. ambigua hydrosol were deemed to be non-toxic. In contrast, the potassium dichromate positive control induced mortality within $4 \mathrm{~h}$

Table 1: The mass of dried plant material, the concentration after resuspension in deionised water, qualitative phytochemical screenings and antioxidant contents of the Kunzea spp. essential oils and hydrosol.

\begin{tabular}{|c|c|c|c|c|}
\hline & & $\begin{array}{l}\text { KA } \\
\text { Oil }\end{array}$ & $\begin{array}{c}\text { KA } \\
\text { Hydrosol }\end{array}$ & KF oil \\
\hline \multirow{9}{*}{ Phenolics } & $\begin{array}{c}\text { Mass of dried } \\
\text { preparation (mg) }\end{array}$ & 2980 & 1780 & 2820 \\
\hline & $\begin{array}{l}\text { Concentration of } \\
\text { stock preparation } \\
(\mathrm{mg} / \mathrm{mL})\end{array}$ & 298 & 178 & 282 \\
\hline & Total phenolics & + & + & + \\
\hline & $\begin{array}{c}\text { Water soluble } \\
\text { phenolics }\end{array}$ & - & - & - \\
\hline & $\begin{array}{c}\text { Water insoluble } \\
\text { phenolics }\end{array}$ & + & + & + \\
\hline & Cardiac glycosides & - & - & - \\
\hline & Saponins & - & - & - \\
\hline & Triterpenes & ++ & - & + \\
\hline & Phytosterols & - & - & - \\
\hline \multirow{3}{*}{ Alkaloids } & Meyer test & - & - & - \\
\hline & Wagner test & - & - & - \\
\hline & Flavonoids & - & - & + \\
\hline \multirow{4}{*}{ Anthraquinones } & Tannins & - & - & - \\
\hline & Free & - & - & - \\
\hline & Combined & - & - & - \\
\hline & Antioxidant capacity & BDT & 1.34 & $\mathrm{BDT}$ \\
\hline
\end{tabular}

+++ indicates a large response; ++ indicates a moderate response; + indicates a minor response; - indicates no response in the assay. $\mathrm{AA}=$ ascorbic acid; $\mathrm{BDT}=$ below detection threshold. Antioxidant capacity determined by DPPH reduction (expressed as mg AA equivalence per g plant material extracted). (results not shown), with $100 \%$ mortality induction seen by $24 \mathrm{~h}$.

To further quantify the effect of $K$. ambigua essential oil concentration on the induction of mortality, it was serially diluted in artificial seawater to test across a range of concentrations in the Artemia nauplii bioassay (Table 2). For comparison, serial dilutions of potassium dichromate were also tested. As an $\mathrm{LC}_{50}$ value of $1680 \mu \mathrm{g} / \mathrm{mL}$ was noted for the $K$. ambigua essential oil (i.e. substantially greater than $1000 \mu \mathrm{g} / \mathrm{mL}$ ), it was also deemed to be non-toxic.

\section{DISCUSSION}

Plant derived remedies are becoming increasingly sought after in the treatment of a myriad of diseases and disorders due both to their perception of greater safety than synthetic drugs, and the failure of current drug regimens to effectively treat many diseases. Our study reports on the growth inhibitory properties of Kunzea spp. essential oils and a hydrosol against a panel of pathogenic bacteria, and on their toxicity. The K. ambigua and $K$. flavescens essential oils were particularly good inhibitors of A. baylyi and P. aeruginosa growth (MIC values 33$500 \mu \mathrm{g} / \mathrm{mL}$ ). As these bacteria can trigger multiple sclerosis in genetically susceptible people, ${ }^{42}$ the Kunzea spp. essential oils have potential in the prevention and treatment of this disease, as well as other diseases caused by $A$. baylyi and $P$. aeruginosa infections. The Kunzea spp. essential oils were also good inhibitors of $P$. mirabilis and $K$. pneumoniae growth (MIC values $124-750 \mu \mathrm{g} / \mathrm{mL}$ ). P. mirabilis can trigger rheumatoid arthritis in genetically susceptible individuals ${ }^{15}$ and $K$. pneumoniae can trigger ankylosing spondylitis in genetically susceptible individuals. ${ }^{12,15}$ Therefore, these essential oils also have potential for the development of rheumatoid arthritis and ankylosing spondylitis inhibitory therapies. Thus, the Kunzea spp. essential oils have potential in the prevention and treatment of multiple autoimmune inflammatory diseases.

The K. ambigua hydrosol was also a good inhibitor of A. baylyi and

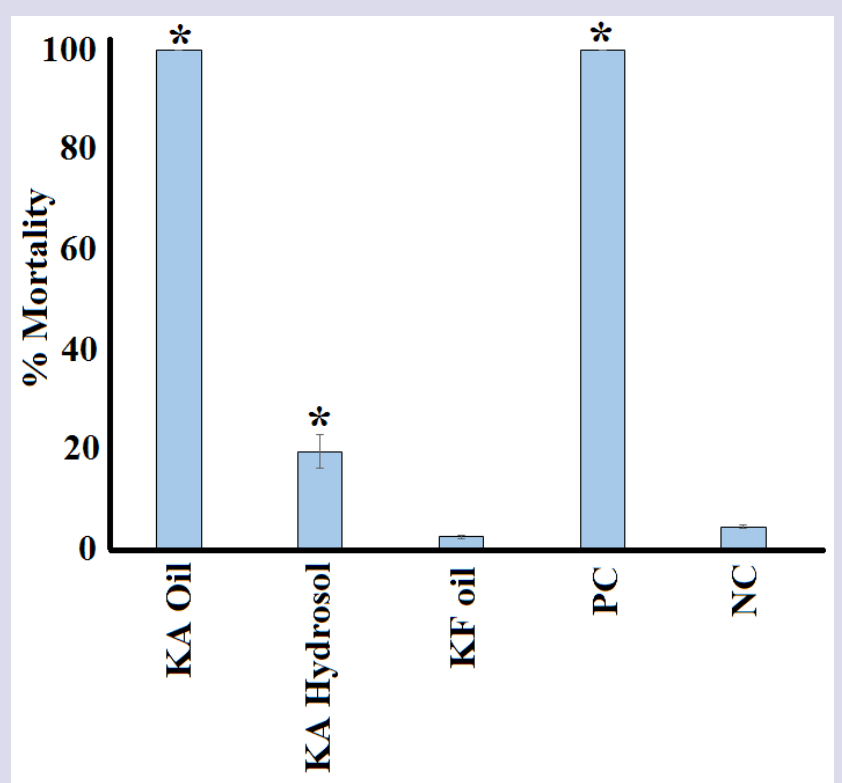

Figure 2: The lethality of the Kunzea spp. essential oils and extracts extracts $(2000 \mu \mathrm{g} / \mathrm{mL})$, potassium dichromate $(1000 \mu \mathrm{g} / \mathrm{mL})$ and a seawater control following $24 \mathrm{~h}$ exposure. $\mathrm{KA}=\mathrm{K}$. ambigua; $\mathrm{KF}=K$. flavescens; $\mathrm{NC}=$ negative (seawater) control; $\mathrm{PC}=$ positive control $(1000 \mu \mathrm{g} / \mathrm{mL}$ potassium dichromate). Results are expressed as mean \pm SEM of at least triplicate determinations. ${ }^{*}$ indicates results that are significantly different to the untreated control $(p<0.01)$. 
Table 2: Minimum inhibitory concentrations $(\mu \mathrm{g} / \mathrm{mL})$ of Kunzea spp. essential oils and extracts against bacterial pathogens.

\begin{tabular}{|c|c|c|c|c|c|c|c|}
\hline & & KA Oil & KA Hydrosol & KF Oil & Amp & Chl & NC \\
\hline \multirow{2}{*}{ A. baylyi (R) } & DD MIC & 1783 & 820 & 580 & ND & ND & ND \\
\hline & LD MIC & 500 & 157 & 157 & - & 2.5 & \\
\hline \multirow{2}{*}{ A. baylyi $(\mathrm{Cl})$} & DD MIC & 1555 & 765 & 748 & ND & ND & ND \\
\hline & LD MIC & 500 & 157 & 330 & - & 2.5 & - \\
\hline \multirow{2}{*}{ A. faecalis } & DD MIC & $>5000$ & - & $>5000$ & ND & ND & ND \\
\hline & LD MIC & 1250 & - & 1250 & 2.5 & 2.5 & - \\
\hline \multirow{2}{*}{ B. cereus } & DD MIC & $>5000$ & - & $>5000$ & ND & ND & ND \\
\hline & LD MIC & 1850 & - & 2560 & 1.25 & 2.5 & - \\
\hline \multirow{2}{*}{ E. aerogines } & DD MIC & - & - & - & ND & ND & ND \\
\hline & LD MIC & - & - & - & 1.25 & 1.25 & - \\
\hline \multirow{2}{*}{ E. coli } & DD MIC & $>5000$ & $>5000$ & $>5000$ & ND & ND & ND \\
\hline & LD MIC & 2560 & $>5000$ & 3280 & 1.25 & 1.25 & - \\
\hline \multirow{2}{*}{ E. faecalis } & DD MIC & $>5000$ & - & $>5000$ & ND & ND & ND \\
\hline & LD MIC & 1760 & - & $>5000$ & - & 2.5 & - \\
\hline \multirow{2}{*}{ K. pneumoniae (R) } & DD MIC & 1587 & - & 476 & ND & ND & ND \\
\hline & LD MIC & 500 & - & 157 & - & 1.3 & - \\
\hline \multirow{2}{*}{ K. pneumoniae $(\mathrm{Cl})$} & DD MIC & 1760 & - & 388 & ND & ND & ND \\
\hline & LD MIC & 500 & - & 124 & - & 1.25 & - \\
\hline \multirow{2}{*}{ P. mirabilis $(\mathrm{R})$} & DD MIC & 832 & 1276 & 628 & ND & ND & ND \\
\hline & LD MIC & 500 & 1150 & 157 & 1.3 & 0.6 & - \\
\hline \multirow[t]{2}{*}{ P. mirabilis $(\mathrm{Cl})$} & DD MIC & 746 & 1083 & 922 & ND & ND & ND \\
\hline & LD MIC & 500 & 924 & 750 & 1.3 & 0.6 & - \\
\hline \multirow{2}{*}{ P. vulgaris } & DD MIC & 1876 & $>5000$ & 2590 & ND & ND & ND \\
\hline & LD MIC & 1250 & $>5000$ & 2200 & 2.5 & 1.3 & - \\
\hline \multirow[t]{3}{*}{$P$. aeruginosa (R) } & DD MIC & $>5000$ & - & $>5000$ & ND & ND & ND \\
\hline & LD MIC & 33 & 350 & 56 & - & 2.5 & - \\
\hline & DD MIC & $>5000$ & - & $>5000$ & ND & ND & ND \\
\hline$P$. aeruginosa $(\mathrm{Cl})$ & LD MIC & 64 & 700 & 128 & - & 2.5 & - \\
\hline Toxicity & Artemia nauplii & 1680 & - & - & & & - \\
\hline
\end{tabular}

Numbers indicate the mean MIC values of triplicate determinations expressed in $\mu \mathrm{g} / \mathrm{mL} . \mathrm{KA}=\mathrm{K}$. ambigua $; \mathrm{KF}=K$. flavescens; $\mathrm{DD}=$ disc diffusion; $\mathrm{LD}=$ liquid dilution; ND = MIC values were not determined as only a single dose was screened; - indicates no inhibition or toxicity at any concentration tested; ${ }^{*}=$ potassium dichromate was used as the positive control. Bold text indicates noteworthy MIC values.

$P$. aeruginosa, and displayed moderate inhibitory activity towards $P$. mirabilis and K. pneumoniae. Therefore, the K. ambigua hydrosol also has potential in the prevention and treatment of rheumatoid arthritis, ankylosing spondylitis and multiple sclerosis. Notably, all other bacteria screened were either completely resistant to the Kunzea spp. essential oils and hydrosol, or displayed only low susceptibility. Interestingly, all of the lower susceptibility species are common causes of food poisoning or food spoilage. Therefore, it is likely these preparations would be ineffective against food poisoning.

The findings reported here also demonstrate that all of the Kunzea spp. essential oils and hydrosol were non-toxic towards Artemia franciscana nauplii, with $\mathrm{LC}_{50}$ values substantially $>1000 \mu \mathrm{g} / \mathrm{mL}$. Whilst our preliminary toxicity studies indicate that these extracts may be safe for therapeutic use, studies using human cell lines are required to further evaluate the safety of these extracts. Furthermore, whilst these studies have demonstrated the potential of the Kunzea spp. essential oils and hydrosol in the development of future antibiotic chemotherapeutics for the prevention and treatment of urinary tract infections, autoimmune diseases (particularly rheumatoid arthritis, ankylosing spondylitis and multiple sclerosis), more work is required to isolate the inhibitory components and determine the mechanism of inhibition.

\section{CONCLUSION}

The results of this study demonstrate the potential of the Kunzea spp. essential oils and hydrosol as inhibitors of pathogenic bacteria growth. Furthermore, their lack of toxicity indicates than they are safe for internal 
as well as topical treatment. Further studies aimed at the purification and identification of bioactive components are required to examine the mechanisms of action of these agents.

\section{ACKNOWLEDGEMENT}

The authors are grateful to Michelle Mendell and Jane Gifkins of Griffith University for providing the clinical bacterial strains used in this study. Financial support for this work was provided by the Environmental Futures Research Institute and the School of Environment and Science, Griffith University, Australia.

\section{CONFLICT OF INTEREST}

The authors report no conflicts of interest.

\section{ABBREVIATIONS}

DMSO: Dimethyl sulfoxide; $\mathbf{L C}_{50}$ : The concentration required to achieve $50 \%$ mortality; MIC: minimum inhibitory concentration; ZOI: zone of inhibition.

\section{REFERENCES}

1. Cowan MM. Plant products as antibacterial agents. Clinical Microbiology Reviews. 1999;12(4):564-82.

2. Bhavnani SM, Ballow $\mathrm{CH}$. New agents for Gram-positive bacteria. Current Opinion in Microbiology. 2000;3(5):528-34

3. Chiariandy CM, Seaforth CE, Phelps RH, Pollard GV, Khambay BP. Screening of medicinal plants from Trinidad and Tobago for antimicrobial and insecticida properties. Journal of Ethnopharmacology. 1999;64(3):265-70.

4. Patwardhan B, Warude D, Pushpangadan P, Bhatt N. Ayurveda and traditiona Chinese medicine: A comparative overview. Evidence-based Complementary and Alternative Medicine. 2005;2(4):465-73.

5. Hostettmann K, Marston A, Ndjoko K, Wolfender J. The potential of African plants as a source of drugs. Current Organic Chemistry. 2000;4(10):973-1010.

6. Paz EA Cerdeiras MP, Fernandez J Ferreira F Moyna P Soubes M, et al. Screening of Uruguayan medicinal plants for antimicrobial activity. Journal of Ethnopharmacology. 1995;45(1):67-70

7. Cock IE. Medicinal and aromatic plants - Australia. In Ethnopharmacology, Encyclopedia of Life Support Systems (EOLSS), 2011. Developed under the auspices of UNESCO. Oxford, UK: EOLSS Publishers. 2011. Available from: http:// www.eolss.net.

8. Cheesman MJ, Ilanko A, Blonk B, et al. Developing new antimicrobial therapies: Are synergistic combinations of plant extracts/compounds with conventional antibiotics the solution?. Pharmacogn Rev. 2017;11(22):57-72. DOI: 10.4103/ phrev.phrev_21_17

9. WHO. Antimicrobial Resistance. World Health Organization. 2016. Available from: http://www.who.int/mediacentre/factsheets/fs194/en/. [Cited on 2019 May 10].

10. Sirdaarta J, Matthews B, Cock IE. Kakadu plum fruit extracts inhibit the growth of the bacterial triggers of rheumatoid arthritis: Identification of stilbene and tannin components. J Funct Food. 2015;17:610-20. DOI: 10.1016/j.jff.2015.06.019

11. Ilanko $A$, Cock IE. The interactive antimicrobial activity of contentional antibiotics and Petalostigma spp. extracts against bacterial triggers of some autoimmune inflammatory diseases. Pharmacogn J. 2019;11(2):292-309. DOI: 10.5530/ pj.2019.11.45

12. Winnett $\mathrm{V}$, Sirdaarta J, White A et al. Inhibition of Klebsiella pneumonia growth by selected Australian plants: Natural approaches for the prevention and management of ankylosing spondylitis. Inflammopharmacol. 2017;25(2):223 35. DOI: 10.1007/s10787-017-0328-

13. Cheesman M, White A, Matthews B, et al. Terminalia ferdinandiana fruit and leaf extracts inhibit methicillin-resistant Staphylococcus aureus growth. Planta Medica. 2019;85(16):1253-62. DOI: 10.1055/a-1013-0434

14. Cock IE, Van Vuuren SF. The traditional use of southern African medicinal plants for the treatment of bacterial respiratory diseases: A review of the ethnobotany and scientific evaluations. J Ethnopharmacol. 2020;113204. DOI: 10.1016/j. jep.2020.

15. Courtney R, Sirdaarta J, Matthews B, et al. Tannin components and inhibitory activity of Kakadu plum leaf extracts against microbial triggers of autoimmune inflammatory diseases. Pharmacogn J. 2015;7(1):18-31. DOI: 10.5530/ pj.2015.7.2

16. Wright MH, Sirdaarta J, Matthews B, et al. Growth inhibitory activity of Kakadu plum extracts against the opportunistic pathogen Clostridium perfringens: New leads in the prevention and treatment of clostridial myonecrosis. Pharmacogn J. 2016;8(2):144-54. DOI: 10.5530/pj.2016.2.8
17. Tiwana G, Cock IE, White A, et al. Use of specific combinations of the triphala plant component extracts to potentiate the inhibition of gastrointestinal bacterial growth. J Ethnopharmacol. 2020;260:112937. DOI: 10.1016/j.jep.2020.112937

18. Mandeville A, Cock IE. Terminalia chebula Retz. fruit extracts inhibit bacterial triggers of some autoimmune diseases and potentiate the activity of tetracycline. Indian J Microbiol. 2018;58(4):496-506. DOI: 10.1007/s12088-0180754-9

19. Arkhipov A, Sirdaarta J, Rayan $\mathrm{P}$ et al. An examination of the antibacterial, antifungal, anti-Giardial and anticancer properties of Kigelia africana fruit extracts. Pharmacogn Commun. 2014;4(3):62-76. DOI: 10.5530/pc.2014.3.7

20. Ilanko P, McDonnell PA, Van Vuuren SF, et al. Interactive antibacterial profile of Moringa oleifera Lam. Extracts and conventional antibiotics against bacterial triggers of some autoimmune inflammatory diseases. S Afr J Bot. 2019;124:420-35

21. Lee CJ, Wright MH, Arnold MSJ, et al. Inhibition of Streptococcus pyogenes growth by native Australian plants: New approaches towards the management of impetigo, pharyngitis and rheumatic heart disease. Pharmacogn Commun. 2016;6(3):164-73. DOI: 10.5530/pc.2016.3.6

22. Wright MH, Sirdaarta J, White A, et al. GC-MS headspace analysis of Terminalia ferdinandiana fruit and leaf extracts which inhibit Bacillus anthracis growth. Pharmacogn J. 2017;9(1):73-82. DOI: 10.5530/pj.2017.1.14

23. McManus $\mathrm{K}$, Wood A, Wright MH, et al. Terminalia ferdinandiana Exell. extracts inhibit the growth of body odour-forming bacteria. International J Cosmetic Sci. 2017;39(5):500-10. DOl: 10.1111/ics.12403

24. Hutchings A, Cock IE. An interactive antimicrobial activity of Embelica officinalis Gaertn. Fruit extracts and conventional antibiotics against some bacterial triggers of autoimmune inflammatory diseases. Pharmacogn J. 2018;10(4):654-62. DOI: $10.5530 / p j .2018 .4 .108$

25. Cock IE. Antimicrobial activity of Callistemon citrinus and Callistemon salignus methanolic extracts. Pharmacogn Commun. 2012:2(3):50-7. DOI: 10.5530/ pc.2012.3.11

26. Wright $\mathrm{MH}$, Matthews $\mathrm{B}$, Arnold MSJ, et al The prevention of fish spoilage by high antioxidant Australian culinary plants: Shewanella putrefaciens growth inhibition. International J Food Sci Technol. 2016;51(3):801-13. DOI: 10.1111/ ijfs. 13026

27. Cock IE. Antimicrobial activity of Leptospermum bracteata and Leptospermum juniperium methanolic extracts. Pharmacogn Commun. 2013:3(3):45-52. DOI: 10.5530/pc.2013.3.9

28. Cock IE. Antibacterial activity of selected Australian plant species. Internet $J$ Microbiol. 2008;6(2)

29. Sautron C, Cock IE. Antimicrobial activity and toxicity of Syzygium australe and Syzygium leuhmanii fruit extracts. Pharmacogn Commun. 2014;4(1):53-60. DOI: 10.5530/pc.2014.1.8

30. Chikowe G, Mpala L, Cock IE. Antibacterial activity of selected Australian Syzygium species. Pharmacogn Commun. 2013;3(4):77-83. DOI: 10.5530/ pc. 2013.4.11

31. Cock IE. Antimicrobial activity of Syzygium australe and Syzygium leuhmannii methanolic extracts. Pharmacogn Commun. 2012;2(2):71-7. DOI: 10.5530/ pc.2012.2.11

32. Qiu XD. Kunzea ambigua chemotypes: their Tasmanian distribution, essential oil compositon and antimicrobial activities. Master's thesis 2008; University of Tasmania. 2008

33. Takarada K, Kimizuka R, Takahashi N, et al. A comparison of the antibacterial efficacies of essential oils against oral pathogens. Oral Microbiology and Immunology. 2004;19(1):61-4.

34. Chikowe GR, Mpala LN, Cock IE. Inhibition of the growth of a panel of pathogenic bacteria by Kunzea flavescens C.T. White and W.D. Francis solvent extractions. Phcogcommn Commun. 2017;7(3):121-8.

35. Webb MA. Bush Sense. Australian Essential oils and aromatic compounds Griffin Press, Adelaide Australia. 2000.

36. Thomas J, Narkowicz CK, Jacobson GA. An examination of the essential oils of Tasmanian Kunzea ambigua, other Kunzea spp. and commercial Kunzea oil. Journal of Essential Oil Research. 2010:22(5):381-5.

37. Shalom J, Cock IE. Terminalia ferdinandiana Exell. fruit and leaf extracts inhibit proliferation and induce apoptosis in selected human cancer cell lines. Nutrit Cancer. 2018;70(4):579-93. DOI: 10.1080/01635581.2018.1460680

38. Cock IE, Wright MH, Matthews B, et al. Bioactive compounds sourced from Terminalia spp. in bacterial malodour prevention: An effective alternative to chemical additives. International J Cosmetic Sci. 2019;41(5):496-508. DOI: 10.1111/ics.12567

39. Fernandez A, Cock IE. Tabebuia impetiginosa (Mart. Ex DC. Mattos) bark extracts inhibit the growth of gastrointestinal bacterial pathogens and potentiate the activity of some conventional antibiotics. Pharmacogn Commn. 2020;10(2):7582. DOI: $10.5530 /$ pc.2020.2.15

40. Cock IE, Wright MH, Matthews $B$, et al. Bioactive compounds sourced from Terminalia spp. in bacterial malodour prevention: An effective alternative to chemical additives. International J Cosmetic Sci. 2019;41(5):496-508. DOI: 10.1111/ics. 12567

41. Rabadeaux $C$, Vallette $L$, Sirdaarta J, et al. An examination of the antimicrobial 
and anticancer properties of Khaya senegalensis (Desr.) A. Juss. bark extracts. Pharmacogn J. 2017;9(4):504-18. DOI: 10.5530/pj.2017.4.82

42. Cock IE, Cheesman MJ. The early stages of multiple sclerosis: New targets for the development of combinational drug therapies. In Neurological Disorders and Imaging Physics. IOP Publishing, UK. 2020;2. DOI: 10.1088/978-0-7503176-7ch2
43. Cock IE, Cheesman MJ. The potential of plants of the genus Syzygium (Myrtaceae) for the prevention and treatment of arthritic and autoimmune diseases. In Bioactive Food as Dietary Interventions for Arthritis and Related Autoimmune Diseases. 2019; Academic Press, USA:. 2019;401-424. DOI: 10.1016/B978-0-12 813820-5.00023-4

\section{PICTORIAL ABSTRACT}

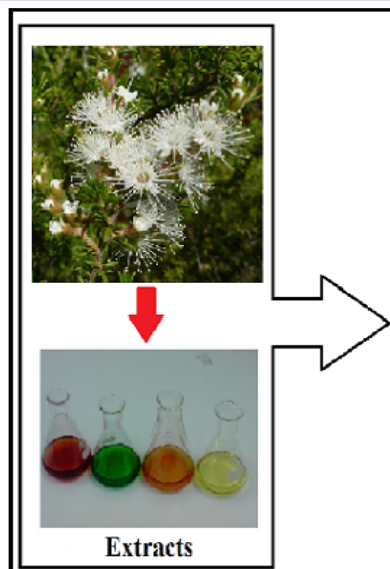

\section{SUMMARY}

- Kunzea spp. essential oils and a hydrosol were screened for antibacterial activity against a panel of bacterial pathogens.

- $\quad$ K. ambigua and $K$. flavescens essential oils displayed broad spectrum antibacterial activity.

- $\quad$ The essential oils were particularly good inhibitors of $A$. baylyi, $K$. pneumoniae, $P$. mirabilis and $P$. aeruginosa growth with $\mathrm{MIC}$ values as low as $33 \mu \mathrm{g} / \mathrm{mL}$.

- The K. ambigua hydrosol was substantially less potent than the corresponding essential oil against all bacteria.

- All Kunzea spp. essential oils and hydrosols were non-toxic in the Artemia nauplii bioassay.

Ankylosing Spondylitis

\section{ABOUT AUTHORS}

Dr. Ian Cock leads a research team in the Environmental Futures Research Institute and the School of Natural Sciences at Griffith University, Australia. His research involves bioactivity and phytochemical studies into a variety of plant species of both Australian and international origin, including Aloe vera, South Asian and South American tropical fruits, as well as Australia plants including Scaevola spinescens, Pittosporum phylliraeoides, Terminalia ferdinandiana (Kakadu plum), Australian Acacias, Syzygiums, Petalostigmas and Xanthorrhoea johnsonii (grass trees). This range of projects has resulted in nearly 200 publications in a variety of peer reviewed journals. 